OPEN ACCESS

Edited by:

Weiwen Zhang,

Tianjin University, China

Reviewed by:

Rajesh P. Rastogi,

Ministry of Environment, Forests and

Climate Change, India

Dmitry A. Los,

Institute of Plant Physiology, Russia

*Correspondence:

Franck Chauvat

franck.chauvat@cea.fr

Specialty section:

This article was submitted to Microbial Physiology and Metabolism,

a section of the journal

Frontiers in Microbiology

Received: 12 August 2016

Accepted: 27 October 2016

Published: 09 November 2016

Citation:

Cassier-Chauvat $C$, veaudor $T$ and Chauvat $F$ (2016) Comparative Genomics of DNA Recombination and

Repair in Cyanobacteria:

Biotechnological Implications.

Front. Microbiol. 7:1809.

doi: 10.3389/fmicb.2016.01809

\section{Comparative Genomics of DNA Recombination and Repair in Cyanobacteria: Biotechnological Implications}

\author{
Corinne Cassier-Chauvat, Théo Veaudor and Franck Chauvat *
}

Institute for Integrative Biology of the Cell, CEA, Centre Nationnal de la Recherche Scientifique (CNRS), Universite Paris-Sud, Université Paris-Saclay, Gif-sur-Yvette Cedex, France

Cyanobacteria are fascinating photosynthetic prokaryotes that are regarded as the ancestors of the plant chloroplast; the purveyors of oxygen and biomass for the food chain; and promising cell factories for an environmentally friendly production of chemicals. In colonizing most waters and soils of our planet, cyanobacteria are inevitably challenged by environmental stresses that generate DNA damages. Furthermore, many strains engineered for biotechnological purposes can use DNA recombination to stop synthesizing the biotechnological product. Hence, it is important to study DNA recombination and repair in cyanobacteria for both basic and applied research. This review reports what is known in a few widely studied model cyanobacteria and what can be inferred by mining the sequenced genomes of morphologically and physiologically diverse strains. We show that cyanobacteria possess many E. coli-like DNA recombination and repair genes, and possibly other genes not yet identified. E. coli-homolog genes are unevenly distributed in cyanobacteria, in agreement with their wide genome diversity. Many genes are extremely well conserved in cyanobacteria (mutMS, radA, recA, recFO, recG, recN, ruvABC, ssb, and uvrABCD), even in small genomes, suggesting that they encode the core DNA repair process. In addition to these core genes, the marine Prochlorococcus and Synechococcus strains harbor recBCD (DNA recombination), umuCD (mutational DNA replication), as well as the key SOS genes lexA (regulation of the SOS system) and sulA (postponing of cell division until completion of DNA reparation). Hence, these strains could possess an E. coli-type SOS system. In contrast, several cyanobacteria endowed with larger genomes lack typical SOS genes. For examples, the two studied Gloeobacter strains lack alkB, lexA, and sulA; and Synechococcus PCC7942 has neither lexA nor recCD. Furthermore, the Synechocystis PCC6803 lexA product does not regulate DNA repair genes. Collectively, these findings indicate that not all cyanobacteria have an E. coli-type SOS system. Also interestingly, several cyanobacteria possess multiple copies of $E$. coli-like DNA repair genes, such as Acaryochloris marina MBIC11017 (2 alkB, 3 ogt, 7 recA, 3 recD, 2 ssb, 3 umuC, 4 umuD, and 8 xerC), Cyanothece ATCC51142 (2 lexA and 4 ruvC), and Nostoc PCC7120 (2 ssb and 3 xerC).

Keywords: cyanobacteria, photoproduction, DNA recombination, DNA repair, genetic instability, insertion sequences, natural transformation, radiation resistance 


\section{INTRODUCTION}

Cyanobacteria, the oldest and most diverse Gram-negative bacteria (Shih et al., 2013) are the only prokaryotes capable of oxygen-evolving photosynthesis (Hamilton et al., 2016). They are viewed as the ancestors of plant chloroplasts (Archibald, 2009), and as major producers of (i) the Earth's oxygenic atmosphere (Schopf, 2011) and (ii) the carbonates sedimentary deposits (Bosak et al., 2013; Benzerara et al., 2014).

Contemporary cyanobacteria produce a tremendous quantity of oxygen, and fix CO2 (Jansson and Northen, 2010), $\mathrm{NO}_{3}$ and $\mathrm{N}_{2}$ (Zehr, 2011) into an enormous biomass that supports a large part of the food chain. $\mathrm{N}_{2}$-fixing cyanobacteria can be used to fertilize soils (Singh et al., 2016), in place of industrial $\mathrm{N}$-fertilizers whose production consumes large amounts of fossil fuels (Grizeau et al., 2015). In colonizing a wealth of wastewater ecosystems that contain high levels of nitrate and phosphate (Abed et al., 2014) and/or heavy metals, cyanobacteria could be used for wastewater treatment (Abed et al., 2014; Singh et al., 2016).

Cyanobacteria produce a wealth of natural products that can influence human health (antioxidants, vitamins, antibacterial, toxins (Williams, 2009; Dittmann et al., 2015; Kleigrewe et al., 2016; Narainsamy et al., 2016). Hence, Arthrospira has served as a human food since time immemorial (Gao, 1998).

Cyanobacteria are also regarded as promising microbial factories for the production of chemicals from nature's most plentiful resources: solar light, water, $\mathrm{CO}_{2}$ (Lai and Lan, 2015; Savakis and Hellingwerf, 2015; Zhou et al., 2016). To reach this objective, it is necessary to (i) introduce and express in cyanobacteria the (heterologous) chemicalsproducing genes they lack; (ii) redirect the photosyntheticallyfixed carbon toward the production of the intended chemicals; (iii) increase the tolerance of the engineered cyanobacteria to the intended products and (iv) maintain, or increase, the genomic stability of the producer strains. These biotechnological works are mainly performed with the unicellular models Synechocystis sp. strain PCC6803, Synechococcus sp. strain PCC7942 (formerly Anacystis nidulans R2) and Synechococcus sp. strain PCC7002 (formerly Agmenellum quadruplicatum PR6) that possess a small sequenced and manipulable genome (http://genome.microbedb.jp/cyanobase/). These cyanobacteria can take up and incorporate extracellular DNA into their chromosome to create insertion, deletion, or replacement mutations (Orkwiszewski and Kaney, 1974; Stevens and Porter, 1980; Grigorieva and Shestakov, 1982). They can also be manipulated with replicative shuttle vectors derived from (i) their endogenous plasmids (Kuhlemeier et al., 1981; Buzby et al., 1983; Chauvat et al., 1986), or (ii) the non-cyanobacterial plasmid RSF1010 (Mermet-Bouvier et al., 1993). Interestingly, this promiscuous plasmid replicates also in Thermosynechococcus elongatus (Mühlenhoff and Chauvat, 1996), Prochlorococcus marinus sp. strain MIT9313 (Tolonen et al., 2006), Leptolyngbya sp. strain BL0902 and Nostoc punctiforme sp. strain ATCC29133 (also registered as PCC73102) (Huang et al., 2010; Taton et al., 2014). Such RSF1010-derived plasmids proved useful tools for in vivo studies of (i) gene expression (Marraccini et al., 1993; Mermet-Bouvier and Chauvat, 1994; Mazouni et al., 1998;
Figge et al., 2000; Mazouni et al., 2003; Huang et al., 2010; Dutheil et al., 2012); (ii) cell division (Mazouni et al., 2004; Marbouty et al., 2009), DNA repair (Domain et al., 2004); (iii) hydrogen production (Dutheil et al., 2012; Sakr et al., 2013; Ortega-Ramos et al., 2014); (iv) insertion sequence (CassierChauvat et al., 1997); and (v) redox metabolism and responses to heavy metals (Poncelet et al., 1998; Marteyn et al., 2009, 2013).

Because of their photoautotrophic lifestyle, cyanobacteria are strongly challenged by DNA damages generated by solar UV rays and photosynthesis (for review see CassierChauvat and Chauvat, 2015), likely explaining their resistance to radiations. Furthermore, many cyanobacteria engineered for biotechnological purposes appeared to be genetically unstable in using DNA recombination to inactivate/eliminate the newly introduced genes of industrial interest. Hence, a better understanding of DNA recombination and repair in cyanobacteria could help increasing their robustness and the genetic stability of the engineered strains. This would represent an important contribution toward the development of an economically viable photo-biotechnology. In this perspective, we used a comparative genomic approach (Table 1 and Supplemental Table 1), to show that cyanobacteria possess a large number of genes homolog to Escherichia coli DNA recombination and repair genes, including the key SOS players lexA and sulA. The presence/absence of these genes and information concerning their function and/or regulation indicate that some cyanobacteria may possess an E. coli-like SOS-type DNA repair system. These findings do not exclude the possible existence in cyanobacteria of other DNA repair genes, not yet identified.

\section{RESULTS AND DISCUSSION Genomic Diversity of Cyanobacteria}

In colonizing most waters (fresh, brackish and marine) and soils, where they face various challenges (Cassier-Chauvat and Chauvat, 2015), cyanobacteria have developed as widely diverse organisms (Narainsamy et al., 2013). Their genomes differ in size (from 1.44 to $12.07 \mathrm{Mb}$ ), ploidy (from two to more than 20 chromosome copies per cell) or GC content (30-60\%), probably as a result from gains and losses of genes transferred by plasmids, insertion sequences (Alam et al., 1991; Cassier-Chauvat et al., 1997) and/or cyanophages (Hess, 2011; Shih et al., 2013). Most cyanobacteria possess a single circular chromosome, ranging from $1.44 \mathrm{Mb}$ in size (the marine symbiotic strain UCYN-A) to $12.07 \mathrm{Mb}$ (Scytonema hofmanni PCC7110) (Dagan et al., 2013). The well-studied strain Synechocystis PCC6803 has a $3.57 \mathrm{Mb}$ chromosome, with a $48 \%$ GC content (http://genome.microbedb.jp/cyanobase/) and a copy number of 10-50 (Labarre et al., 1989; Griese et al., 2011). For the other models the values are $2.69 \mathrm{Mb}, 55 \%$ and 2-5 for Synechococcus PCC7942 (Mann and Carr, 1974; Griese et al., 2011; Watanabe et al., 2015); and $3.00 \mathrm{Mb}, 50 \%$, and likely 2-5 for Synechococcus PCC7002 (Griese et al., 2011; Watanabe et al., 2015). Synechocystis PCC6803 also has seven plasmids, ranging from $2.3 \mathrm{~Kb}$ (Chauvat et al., 1986) to $119 \mathrm{vKb}$ 
TABLE 1 | Reference of the genes from Synechocystis PCC6803 (sll or slr), E.coli (eco) or B.subtilis (BSU) in the MBGD data base (http://mbgd.genome.ad.jp/) used for searching their homologs in the studied cyanobacteria.

\begin{tabular}{|c|c|c|}
\hline Name & Protein function & Gene id \\
\hline uvrA & UvrA, excinuclease $A B C$ subunit $A$ & slr1844 \\
\hline uvrB & UvrB, excinuclease ABC subunit B & sll0459 \\
\hline uvrC & UvrC, excinuclease $A B C$ subunit $C$ & sll0865 \\
\hline uvrD & UvrD, excinuclease ABC subunit C/helicasell & sll1143 \\
\hline recA & RecA, recombinase $A$ & sll0569 \\
\hline recBec & $\begin{array}{l}\text { RecB exonuclease V (RecBCD complex), beta } \\
\text { subunit }\end{array}$ & eco:B2820 \\
\hline recBcy & $\begin{array}{l}\text { Contains hhH domain and of nuclease of recB } \\
\text { family }\end{array}$ & sll1686 \\
\hline recC & $\begin{array}{l}\text { recC exonuclease } \mathrm{V} \text { (RecBCD complex), gamma } \\
\text { chain }\end{array}$ & eco:B2822 \\
\hline $\operatorname{rec} D$ & $\begin{array}{l}\text { recD exodeoxyribonuclease } \mathrm{V} \text {, subunit alpha/ TraA } \\
\text { family helicase }\end{array}$ & eco:B2819 \\
\hline recF & Recombination protein F RecF & sll1277 \\
\hline recG & ATP-dependent DNA helicase RecG & slr0020 \\
\hline recJec & recJ ssDNA exonuclease, 5' -> 3'-specific & eco:B2892 \\
\hline recJcya & single-stranded-DNA-specific exonuclease RecJ & sll1354 \\
\hline $\operatorname{rec} N$ & DNA repair protein $\mathrm{RecN}$ & sll1520 \\
\hline recQec & ATP-dependent DNA helicase RecQ & eco:B3822 \\
\hline recQcy & ATP-dependent DNA helicase RecQ & slr1536 \\
\hline recR & Recombination protein F RecF & slr1426 \\
\hline recO & DNA gap repair protein & sll/eco:B2565 \\
\hline rUVA & Holliday junction DNA helicase RuvA & sll0876 \\
\hline ruvB & Holliday junction DNA helicase RuvB & sll0613 \\
\hline ruvC & Holliday juction resolvase RuvC & sll0896 \\
\hline muth & mutH methyl-directed mismatch repair protein & eco:B2831 \\
\hline mutL & mutL DNA mismatch repair protein & slr1199 \\
\hline mutM & Formamidopyrimidine-DNA glycosylase & slr1689 \\
\hline mutS1 & DNA mismatch repair protein MutS & sll1165 \\
\hline mutS2 & $\begin{array}{l}\text { recombination and DNA strand exchange inhibitor } \\
\text { protein }\end{array}$ & sll1772 \\
\hline mutT & $\begin{array}{l}\text { DNA mismatch repair protein Mutator Mut_like } \\
\text { protein }\end{array}$ & slr1134 \\
\hline mutY1 & A/G specific adenin glycosylase yfhQ & eco:B2961 \\
\hline umuC & $\begin{array}{l}\text { umuC translesion error-prone DNA polymerase } \mathrm{V} \\
\text { subunit; }\end{array}$ & eco:B1184 \\
\hline umuD & SOS response UmuD protein & sll5123 \\
\hline lexA & lexA SOS function regulatory protein & sll1626 \\
\hline$s s b$ & ssb single-stranded DNA-binding protein & slr0925 \\
\hline $\operatorname{din} B$ & DNA polymerase IV & eco:B0231 \\
\hline comA & competence protein comEA, comA & slr0197 \\
\hline comE & competence protein comEC, comEA comE & sll1929 \\
\hline comFA & Competence protein ComF operon protein1 & BSU35470 \\
\hline
\end{tabular}

(Continued)
TABLE 1 | Continued

\begin{tabular}{lll}
\hline Name & Protein function & Gene id \\
\hline comFB & Competence protein ComFB protein2 & BSU35760 \\
comFC & Competence protein ComFC protein 3 & BSU35450 \\
phR & phr deoxyribopyrimidine photolyase & slr0854 \\
alkB & alkB oxidative demethylase of N1 or N3 & eco:B2212 \\
& methylcytosine DNA lesions & \\
& & \\
xerC & integrase recombinase & slr0733 \\
ogt/ada & O6 methylguanine transferase/ fused DNA binding & eco:B1335 \\
& transcritional regulator & and BSU13540 \\
& & \\
sulA & sulA cell division inhibitor & slr1223 \\
radA & sms DNA repair protein RadA & slr0448 \\
\hline
\end{tabular}

(http://genome.microbedb.jp/cyanobase/); $\quad$ Synechococcus PCC7942 has one plasmid (46 Kb); and Synechococcus PCC7002 has seven plasmids $(4.8-186 \mathrm{~Kb})$. Interestingly, Cyanothece ATCC51142 possesses two chromosomes (one circular, $4.39 \mathrm{Mb}$; and one linear, $0.4 \mathrm{Mb}$ ) and four plasmids $(10-39 \mathrm{~Kb})$, whereas the marine strains Prochlorococcus and Synechococcus have a small chromosome (1.6-2.7 Mb), and no plasmids (Scanlan et al., 2009).

As a consequence of their genomic diversity, cyanobacteria produce a wealth of metabolites (Dittmann et al., 2015; Kleigrewe et al., 2016), display different cell morphologies (Cassier-Chauvat and Chauvat, 2014) and can differentiate cells, akinetes and/or heterocysts, respectively dedicated to cell survival in adverse conditions (Chauvat et al., 1982) or the fixation of atmospheric nitrogen (Flores and Herrero, 2010).

\section{Cyanobacteria can be Resistant to Radiations}

Because of their photoautotrophic lifestyle, cyanobacteria are strongly challenged by solar UV rays and reactive oxygen species generated by photosynthesis (Cassier-Chauvat and Chauvat, 2015). Consequently, Synechocystis PCC6803 and Synechococcus PCC7942 are found to be more resistant to UV than the (nonphotosynthetic) bacterium E. coli where DNA repair is best known (Baharoglu and Mazel, 2014). Synechocystis PCC6803 is also more resistant to gamma rays than Synechococcus PCC7942 and E. coli in that order (the doses yielding $10 \%$ survival are 660, 230, and $130 \mathrm{~Gy}$, respectively (Domain et al., 2004). Other cyanobacteria are even more radioresistant, almost as the champion bacterium Deinococcus radiodurans [100\% survival at 5kGy (Moseley and Mattingly, 1971; Ito et al., 1983)]. These radiation-resistant cyanobacteria are Chroococcidiopsis [10\% survival to $4-5 \mathrm{kGy}$ of gamma rays (Billi et al., 2000)], three Anabaena strains [they can grow at $5 \mathrm{kGy}$ (Singh et al., 2010)] and Arthrospira PCC 8005 [it grows at 800 Gy (Badri et al., 2015)]. Thus, cyanobacteria might be used in the future for leaching (and/or sequestration) of radionuclides (Acharya and Apte, 2013). 


\section{Cyanobacteria can be Naturally Competent for Genetic Transformation Mediated by DNA Recombinations}

The naturally transformable cyanobacteria Synechococcus PCC7942, Synechococcus PCC7002, and Synechocystis PCC6803 can take up extracellular DNA and to recombine it into their own genome (Orkwiszewski and Kaney, 1974; Stevens and Porter, 1980; Grigorieva and Shestakov, 1982). This capability served to create a wealth of insertions, deletions or replacement mutations (Lai and Lan, 2015; Savakis and Hellingwerf, 2015; Zhou et al., 2016).

Natural transformation is best studied in Bacillus subtilis and Helicobacter pylori (Dorer et al., 2011). DNA transported into the cytosol by the Com proteins (com for competence) is integrated into the recipient genome by the RecA, RecG, and RuvABC recombination proteins.

The com genes (Table 1) are widely distributed in cyanobacteria (Supplemental Table 1). Synechocystis PCC6803, Synechococcus PCC7942, and Synechococcus PCC7002 harbor the comAEF genes (Supplemental Table 1). The Synechocystis PCC6803 genes comA and comF truly operate in transformation (Yoshihara et al., 2001), and comF is also involved in phototactic motility (Nakasugi et al., 2006). The role of comE could not be verified because the comE-depleted mutant dies rapidly (Yoshihara et al., 2001). By contrast, the Prochlorococcus cyanobacteria endowed with small genomes have no comAEF genes, excepted $P$. marinus MIT9303, and $P$. marinus MIT9313 that possess comA, come, and ComF (Supplemental Table 1). These strains also have the $\operatorname{rec} A, \operatorname{rec} G$, and $\operatorname{ruv} A B C$ genes (Supplemental Table 1). We have verified in Synechocystis PCC6803 that $r u v B$ operates in genetic transformation (Domain et al., 2004). These finding suggest that $P$. marinus MIT9313 may be transformable in appropriate conditions.

Recently, the CRISPR/Cas9 genome editing system, which enhances the recombination efficiency and accelerates the process for chromosome segregation, was used for efficient genome editing in cyanobacteria ( $\mathrm{Li}$ et al., 2016; Wendt et al., 2016).

\section{Cyanobacteria Genetically Engineered for Biotechnological Purposes can be Genetically Instable}

Microbial organisms can genetically adapt themselves to their "laboratory" environment. This phenomenon explains the phenotypic differences observed between various sub-strains of the same organism cultivated in diverse laboratories. Hence, the four laboratory sub-strains of Synechocystis PCC6803 with different cell motility and/or ability to feed from glucose, harbor mutations, insertion or deletion, as compared to each others (Okamoto et al., 1999; Kanesaki et al., 2012; Trautmann et al., 2012).

Genetic instability can also be observed in strains genetically engineered for the synthesis of chemicals, where it can decrease the amplitude and/or durability of production. Genetic instability correlates with the toxicity of the products, and homologous recombination between repeated DNA motifs (Gellert and Nash,
1987; Holder et al., 2015), which are frequent in cyanobacteria (Elhai, 2015).

In the 61 articles reporting the genetic engineering of a model cyanobacterium for the synthesis of a biotechnological product, the level of production were analyzed only during short periods of times (usually not more than 30 days after the generation of the producer strains; Lai and Lan, 2015). Consequently, we know very little regarding genome (in)stability in engineered cyanobacteria growing under laboratory conditions. This genome (in)stability is an important issue in large industrial cultures that require many cell divisions of the engineered cyanobacteria. The longer the cultivation, the higher the probability of selecting spontaneous mutations decreasing the synthesis of the product to increase cell fitness.

A few studies reported the genetic instability of engineered cyanobacteria. We observed this phenomenon while attempting to use Synechocystis PCC6803 for the production of a uniformly ${ }^{14} \mathrm{C}$-labeled mouse urokinase (a serine protease). The urokinase producing plasmid, which replicated stably in the $\mathrm{rec}^{-}$mutant of E. coli, invariably lost part of the urokinase gene upon propagation in Synechocystis PCC6803 (Chauvat et al., 1988). Another Synechocystis PCC6803 strain harboring Pseudomonas aeruginosa genes cloned its chromosome (at the slr0168 neutral docking site) for lactic acid production, happened to rescue its growth by introducing a duplication ( $\sim 160 \mathrm{bp})$ that generated premature stop codons into the Pseudomonas (NADPH/NADH) transhydrogenase gene (Angermayr et al., 2012).

Similarly, the Synechococcus PCC7942 strain harboring the Pseudomonas syringae gene ( $\mathrm{efe}$ ) encoding the ethylene-forming enzyme (Fukuda et al., 1992; Sakai et al., 1997), managed to introduce short nucleotide insertions in efe to stop ethylene production and recover a healthy growth (Takahama et al., 2003). Another recombinant Synechococcus PCC7942 strain could introduce a missense mutation in the E. coli atoD gene (acetoacetyl-CoA transferase) to decrease isopropanol production (Kusakabe et al., 2013).

In Synechococcus PCC7002, a recombinant strain managed to loose mannitol synthesis and recover healthy growth, in introducing a single-base deletion generating a stop codon in its E. coli mannitol-1-phosphate dehydrogenase $m t l D$ gene (Jacobsen and Frigaard, 2014).

The Synechocystis PCC6803 and Synechococcus PCC7002 recombinant strains producing the Zymomonas mobilis pyruvate decarboxylase enzyme (PDC) for ethanol production, could introduce mutations, insertions, deletions or mobile genetic elements (insertion sequences) into the $p d c$ gene to stop ethanol production (Schulze et al., 2015).

Insertion sequences (ISs) are approximately $1 \mathrm{kbp}$ long DNA segments found in the genome of most living organisms, where they can interrupt genes (Bennett, 2004). Generally, an IS comprises an inverted repeat DNA sequence flanking one or two genes encoding the mobilization protein (transposase), which drives the excision and reinsertion of IS in genomes.

Many cyanobacterial chromosomes and/or plasmids harbor a few or numerous copies of ISs, as the widely distributed IS families IS4, IS5, IS630 and IS200-605, which are regarded as ancestral (Lin et al., 2011). Though several P. marinus strains 
harboring a small genome have no IS, the frequencies of IS do not systematically increase with the genome size. Indeed, IS represent $10 \%$ of the $5.8 \mathrm{Mb}$ genome of Microcystis aeruginosa NIES843, $1.5 \%$ of the $3.95 \mathrm{Mb}$ genome of Synechocystis PCC6803, and 1\% of the 7.2 Mb genome of Nostoc (Anabaena) PCC7120 (Lin et al., 2011). Consistent with the findings that transposase genes can be induced by stresses (Hernández-Prieto et al., 2016), several studies employing a positive selection procedure showed that ISs can be truly mobile in cyanobacteria. First, a recombinant Nostoc (Anabaena) PCC7120 strain harboring a plasmid encoding the $B$. subtilis SacB enzyme (levan sucrase), which kills cells incubated in the presence of sucrose, generated sucrose resistant mutants resulting from the disruption of the $s a c B$ gene by a mobile IS895 element (Alam et al., 1991).

Similarly, an IS5 element of Synechocystis PCC6803 was shown to be mobile in rescuing the growth of a conditionally lethal mutant by disrupting the repressor gene that normally blocks the transcription of an essential ferredoxin-encoding gene (CassierChauvat et al., 1997; Poncelet et al., 1998). Other recently transposed IS4 elements were identified through Southern blotting and DNA sequencing analysis of three Synechocystis PCC6803 sub-strains (Okamoto et al., 1999).

In addition, the presence of multiple copies of an IS in a genome can promote homologous recombination, leading to genome rearrangements (inversions or deletions; Gellert and Nash, 1987) that can modify cell fitness. Moreover, ISs can be transferred between genomes by horizontal gene transfer mechanisms. Thus, ISs are an important force in genome evolution (Bennett, 2004).

So far very few studies attempted to decrease or eliminate the negative influence of IS on biotechnological production. In Corynebacterium glutamicum, the deletion of two major IS elements generated a cell chassis with an increased ability to stably produce recombinant proteins (Choi et al., 2015). A similar strategy could be tested in the genetically manipulable cyanobacteria Synechococcus PCC7942 and Synechococcus PCC7002 because they possess only one and ten transposase genes, respectively (http://genome.microbedb.jp/cyanobase/). In contrast, an IS-deletion strategy is not an appealing for Synechocystis PCC6803 that possesses 128 transposase genes.

In $E$. coli, the stable propagation of recombinant DNA (usually cloned in plasmids) is achieved in strains where $\operatorname{rec} A$, the key DNA-recombination gene (Baharoglu and Mazel, 2014), has been inactivated to prevent unexpected DNA rearrangements. All cyanobacteria possess a $\operatorname{rec} A$ gene (Acaryochoris marima MBIC11017 has 7 recA genes, Supplemental Table 1). The recA gene appeared to be indispensable to cell life in Synechococcus PCC7002 (Murphy et al., 1990), whereas it could be deleted from all chromosome copies in Synechocystis PCC6803 (Minda et al., 2005). The Synechocystis PCC6803 recA null mutant is bound to be of limited biotechnological interest because it is not only sensitive to UV-C, but also to standard fluence of white light required for cell growth. Furthermore, in being defective in DNA recombination a $r e c A^{-}$mutant is not appropriate for genetic manipulation of the cyanobacterial chromosome (cloning of heterologous genes encoding the synthesis of biotechnological products and/or deletion of endogenous genes limiting the intended production).

An interesting way to limit genetic instability of engineered bacteria is to clone the product-synthesizing genes under the control of regulatable expression signals to afford a usercontrolled synthesis of the potentially harmful product. Using such regulatory signals, one can grow the engineered strain up to a large biomass, before triggering the synthesis of the intended product, which, otherwise, could have impaired the fitness and/or the genetic stability of the producer.

In cyanobacteria gene expression can be regulated by (i) light ( $p s b A 2$ promoter), (ii) the IPTG metabolite (lac promoter/repressor system), (iii) metals [cyanobacterial promoters coaT, ziaA, etc (Berla et al., 2013; Zhou et al., 2016)], or (iv) the growth temperature [lambda phage $p \mathrm{R}$ promoter controlled by the cI857 temperature-sensitive repressor (Ferino and Chauvat, 1989; Mermet-Bouvier and Chauvat, 1994)]. As put forward by other workers (Berla et al., 2013) an ideal system should combine the following properties.

(a) "It should be inactive in absence of inducer";

(b) "It should produce a predictable response to a given concentration of a regulator";

(c) "The inducer should have no harmful effect on the host organism";

(d) "The inducer should be cheap and stable under the growth conditions of the host";

(e) "The inducible system should act orthogonally to the host cell's transcriptional program (ideal transcriptional repressors should not bind to native promoters.)"

In our laboratory, we often used the temperature-controlled system that appeared to combine most of these advantageous properties (Dutheil et al., 2012; Marteyn et al., 2013; OrtegaRamos et al., 2014) and references therein. This system tightly controls gene expression proportionally to growth temperatures i.e., absence of expression at temperature $\leq 30^{\circ} \mathrm{C}$ (the standard growth temperature of our favorite cyanobacterium Synechocystis PCC6803); intermediary expression at intermediate temperature $34-37^{\circ} \mathrm{C}$; and strong expression at $39^{\circ} \mathrm{C}$ (where Synechocystis PCC6803 keep growing well). For instance, when this system was used to control the production of the heterologous enzymes chloramphenicol-acetyl-transferase and beta-galactosidase, which possess an easily quantified activity, the values were respectively $\leq 3$ units $\left(30^{\circ} \mathrm{C}\right) ; 700-1000$ units $\left(34-37^{\circ} \mathrm{C}\right)$ and 2000-4000 units $\left(39^{\circ} \mathrm{C}\right)$ (Ferino and Chauvat, 1989; MermetBouvier and Chauvat, 1994). Hence this system can be also used for basic research that requires the construction of conditionally-lethal mutants (Poncelet et al., 1998; Sakr et al., 2013).

\section{Distribution of Direct DNA-Damages Reversal Genes in Cyanobacteria}

From bacteria to higher eukaryotes, cells are continuously exposed to DNA damages generated by their own metabolism (Imlay, 2013) and/or exogenous sources (radiations, chemicals, etc). DNA lesions are repaired by conserved pathways that 
have been extensively studied in E. coli (Baharoglu and Mazel, 2014). The simplest system, the direct damage reversal pathway, removes only the base-modifying agent in one single step (Resende et al., 2011) catalyzed by the AlkB demethylase, the Ogt alkyltranferase, and the Phr (photorepairs of pyrimidine) photolyase.

Using a comparative genomic approach, we found that the 76 cyanobacterial genome sequences in the MBGD data base (http://mbgd.genome.ad.jp/) possess many genes orthologous to E. coli DNA recombination and repair genes. The $p h r, a l k B$ and ogt orthologs (Table 1) are distributed unevenly in cyanobacteria (Supplemental Table 1). The phr gene is present in almost all cyanobacteria including some, but not all, $P$. marinus strains endowed with a small genome (1.6-2.7 Mb). In agreement with the light fluence they receive in their oceanic biotopes (Biller et al., 2015), the high-light-adapted strains P. marinus MIT9515 and P. marinus MED4 possess phr, whereas the low-lightadapted strains $P$. marinus MIT9303 and P. marinus MIT9313 lack phr (Supplemental Table 1), and are light sensitive (Biller et al., 2015). The alkB and ogt genes are less frequent than phr. All three genes alkB, ogt, and phr are simultaneously present in several (twelve) studied cyanobacteria, such as Nostoc (Anabaena) PCC7120 (filamentous), and Cyanothece PCC7425 (unicellular) where ogt is duplicated. The other (evolutionary distant) unicellular models Synechocystis PCC6803, Synechococcus PCC7942, and Synechococcus PCC7002 possess phr (Supplemental Table 1). Synechocystis PCC6803 has alkB but not ogt, Synechococcus PCC7942 has ogt (duplicated) but not alkB, and Synechococcus PCC7002 has neither alkB nor ogt. Interestingly, the symbiotic (marine) cyanobacterium UCYN-A has no $p h r$, alkB, and ogt, in agreement with the fact that it possesses the smallest genome $(1.44 \mathrm{Mb})$. The other symbiotic strain Acaryochloris marina MBIC11017 endowed with a larger genome $(8.36 \mathrm{Mb})$ has two alkB, three ogt (including one on a plasmid) but no phr (Supplemental Table 1).

\section{Distribution of Nucleotide Excision DNA Repair Genes in Cyanobacteria}

This pathway removes distortions of the double helix of DNA (pyrimidine dimers or DNA intra-strand cross-links), by excising a small group of bases (Baharoglu and Mazel, 2014). In E. coli the two-proteins complex UvrAB recognizes the DNA lesion; UvrC generates a double incision on both sides of the lesion and the UvrD helicase removes the single-strand DNA carrying the lesion. The missing DNA is re-synthesized by the DNA polymerase I ( $\mathrm{Pol}$ I), and subsequently sealed by a ligase.

All tested cyanobacterial genomes possess the uvrABCD single-copy genes (Supplemental Table 1), where uvrA and $u v r B$ are not organized in operon (Supplemental Figure 1), unlike what occurs in E. coli. In some cyanobacterial genomes $u v r A, u v r B, u v r C$, and/or $u v r D$ are clustered with another DNA repair gene, such as phr or recN (gene clusters a and $c$ in Supplemental Table 1 and Supplemental Figure 1). In the radiation-resistant cyanobacterium Arthrospira PCC8005, uvrBCD were found to be upregulated by gamma rays (no information is provided for $u v r A$ ) (Badri et al., 2015).

\section{Distribution of Methyl-Directed DNA Mismatch Repair Genes in Cyanobacteria}

This pathway corrects the mispaired DNA bases generated by replication errors (Putnam, 2016). In E. coli, MutS recognizes mispaired DNA bases and coordinates with MutH and MutL (nucleases), MutM, MutT and MutY (DNA glycosylases) and UvrD (helicase) to direct excision of the newly synthesized DNA strand (not yet methylated at GATC sites by the Dam methylase) up to the mismatch. The resulting gap is filled up by a DNA polymerase (likely PolIII) and a ligase (Putnam, 2016).

All tested cyanobacteria have mutM (Supplemental Table 1), which was shown in Synechococcus PCC7942 to operate in resistance to high light (Mühlenhoff, 2000). All cyanobacteria possess $m u t S$, which occurs in two copies, excepted in Crinalium epipsammum PCC 9333 (Supplemental Table 1). By contrast, $m u t H$ is absent in all cyanobacteria. The genetic diversity of cyanobacteria is well illustrated with the presence/absence of mutL, mutt, and mutY (Supplemental Table 1), which lies in front of recR in a few cyanobacterial genomes (Table 1 and Supplemental Figure 1). Several P. marinus strains lack mutL, mutt, and mutY (Supplemental Table 1). In Arthrospira PCC8005 (radiation-resistant) mutST were upregulated by gamma rays (Badri et al., 2015).

The model strains Synechocystis PCC6803, Synechococcus PCC7942, Synechococcus PCC7002 and Nostoc (Anabaena) PCC7120 possess mutL, mutM, mutS (duplicated), mutT (excepted Synechococcus PCC7002), mutY (excepted Synechococcus PCC6803 and Nostoc PCC7120) (Supplemental Table 1). Thus, Synechococcus PCC7942 is best suited to study all these genes through deletion/over-expression in the otherwise same genetic context.

\section{Distribution of Recombinational DNA Repair Genes in Cyanobacteria}

This pathway repairs double-stranded breaks and crosslinks. In E. coli, single-strand DNA nicks are enlarged by the RecQ helicase and RecJ exonuclease, into gaps that are recognized by the proteins RecFOR. The double-strand DNA breaks (DSB) are recognized by the RecBCD proteins that form an exonuclease/helicase complex. Subsequently, the RecFOR/RecBCD complexes (and RecN) load RecA to initiate homologous recombination and DNA repair. RecA mediates synapsis, forming a Holliday junction. Replication fills gaps. RecG, Ssb (single-stranded DNA binding protein) and RuvAB mediate branch migration (stimulated by RadA), and RuvC resolves the junctions (Baharoglu and Mazel, 2014).

DNA recombination also involves the XerC-XerD complex. It converts dimers of the chromosome into monomers to permit their segregation during cell division, and it contributes to the segregational stability of plasmids (Resende et al., 2011; Buljubašic et al., 2013).

In many bacteria, such as $H$. pylori and B. subtilis the AddA and $\mathrm{AddB}$ proteins replace RecB and RecC, respectively (Dorer et al., 2011; Wigley, 2013).

All cyanobacteria contain $r e c A$, which occurs as seven copies in the large genome $(8.36 \mathrm{Mb})$ of A. marina MBIC11017. 
Four of these recA genes, possibly originating from gene duplication (Swingley et al., 2008), are located on four separate plasmids, while the other recA belong to the chromosome (Supplemental Table 1).

Like $\operatorname{rec} A, \operatorname{rad} A$ and $\operatorname{rec} G$ are present in all cyanobacteria, and $\mathrm{radA}$ is duplicated in Cyanothece PCC7425, M. aeruginosa NIES-843 and UCYNA (Supplemental Table 1). It is the only duplicated gene in the very small UCYNA genome (1.44 Mb).

Many cyanobacteria have two copies of recJ and recQ genes. They are noted as recJ $J_{e c}$ or $r e c J_{c y}$, or $r e c Q_{e c}$ or $r e c Q_{c y}$ (ec for E. coli, cy for cyanobacteria), according to their high ( $r e c J_{e c}$, $\left.r e c Q_{e c}\right)$ or low $\left(r e c J_{c y}, r e c Q_{c y}\right)$ sequence similarity with their $E$. coli counterparts (Table 1 and Supplemental Table 1). This is true for Synechococcus PCC7002 and Nostoc PCC7120, where these duplicated genes can be studied and compared through deletion/over-expression. In Arthrospira PCC8005 (radiationresistant), recGJQ were found to be upregulated by gamma rays (Badri et al., 2015). In contrast a few cyanobacteria has neither recJ nor recQ, as $P$. marinus MIT9515 (Supplemental Table 1). Also interestingly, the low-light-adapted $P$. marinus MIT9313 and $P$. marinus MIT9303 possess the recQ genes (and ogt and the competence genes comE and comFC), which are not present in other Prochlorococcus (Supplemental Table 1). In addition, both P. marinus MIT9313 and P. marinus MIT9303 lack the phr gene, which occurs in other Prochlorococcus (Supplemental Table 1), in agreement with their light-sensitivity (Biller et al., 2015). Collectively, these findings support the proposal that $P$. marinus MIT9303 and P. marinus MIT9313 belong to the same clade, which diverged early from the other Prochloroccus clades (Sun and Blanchard, 2014; Biller et al., 2015).

Almost all cyanobacteria have the single-copy genes $r e c F$, recO and recR, excepted Cyanobacterium aponinum PCC10605, C. epipsammum PCC9333 and Cylindrospermum stagnale PCC7417 which lack recR (Supplemental Table 1)

The $\operatorname{rec} B C D$ genes are less conserved in cyanobacteria. For instance, the strain UCYN-A that possesses recFOR has no recBCD genes (Supplemental Table 1). Most $P$. marinus strains and several marine Synechococcus strains possess recBCD. Most of these strains possess two $\operatorname{rec} B$ copies, noted $r e c B_{e c}$ (good similarity with $E$. coli $r e c B$ ) or $\operatorname{rec} B_{c y}$ (cy for cyanobacteria, low similarity with $E$. coli $r e c B$ ). In these strains, $\operatorname{rec} B_{e c}$ belongs to the same genomic region than $\operatorname{rec} C$ and $\operatorname{rec} D$ (cluster $\mathrm{f}$ in Supplemental Table 1 and Supplemental Figure 1). In a few other cyanobacteria recD is duplicated (Microcoleus PCC7113) or triplicated (A. marina MBIC11017 and N. punctiforme PCC73102), irrespectively of the presence /absence or $r e c B_{e c}$ and $\operatorname{rec} B_{c y}$ (Supplemental Table 1). The well-studied model cyanobacteria lack $r e c B$, $\operatorname{rec} C$, or $r e c D$. Both Synechocystis PCC6803 and Nostoc (Anabaena) PCC7120 lack rec $B_{e c}$ and $r e c C$, while both Synechococcus strains PCC7942 and Synechococcus PCC7002 lack recCD.

The $\operatorname{recN}$ gene is present in all cyanobacteria to the noticeable exception of Chamaesiphon minutus PCC6605. Interestingly the $\mathrm{RecN}$ protein was absent in mature heterocysts of Anabaena PCC7120, the differentiated nitrogen-fixing cells that have lost the ability to divide (Hu et al., 2015).
In some cyanobacteria a few rec genes are clustered together (recBCD see cluster $\mathrm{f}$ in Supplemental Table 1 and Supplemental Figure 1), or with other DNA repair genes, including uvrA (cluster a) or mutY (cluster n; Supplemental Table 1 and Supplemental Figure 1).

All cyanobacteria have a $s s b$ gene, which is repeated in a few strains. For instance, ssb is duplicated in Nostoc (Anabaena) PCC7120 and A. marina MBIC11017), while it is triplicated in Chroococcidiopsis thermalis PCC7203 and quadruplicated in Cyanothece PCC7822 (Supplemental Table 1). In these cyanobacteria (excepted Nostoc (Anabaena) PCC7120) one ssb copy is propagated on a plasmid. One of the two Nostoc PCC7120 $s s b$ genes, (alr0088, but not alr7579) was shown to be involved in the tolerance to UV and mitomycin $\mathrm{C}$ which causes formation of DNA adducts (Kirti et al., 2013).

The $\operatorname{ruv} A B C$ genes are present in all cyanobacteria, to the noticeable exception of $G$. kilaueensis JS1 which lacks ruvC (Supplemental Table 1). The $\operatorname{ruvA}$ and $\operatorname{ruvB}$ genes are not adjacent unlike their operonic E. coli counterparts. Furthermore, ruvA is duplicated in Trichodesmium erythraeum ISM101, while ruvC is quadruplicated in Cyanothece ATCC51142 and quadruplicated in Cyanothece PCC7822 (Supplemental Table 1). In Synechocystis PCC6803 ruvB was shown to be dispensable to cell growth in standard laboratory conditions, and to operate in the resistance to $\mathrm{UV}$ and $\mathrm{H}_{2} \mathrm{O}_{2}$ (Domain et al., 2004).

Unlike $\operatorname{rec} A N$ and $\operatorname{ruv} A B C, \operatorname{xerC}$ is a rare gene in cyanobacteria (Supplemental Table 1). It occurs in a single copy in a few strains, as UCYN-A, Synechococcus PCC7942, Synechococcus PCC7002 and Synechocystis PCC6803, or in several copies in Cyanothece PCC7424, Cyanothece PCC7822 (two copies), Nostoc (Anabaena) PCC7120 (three copies), A. marina MBIC11017 (eight copies).

In bacteria, homologous recombination preferentially initiates at highly repeated, oligomeric DNA sequences designated as Chi (crossover hotspot instigator) sites. In E. coli, the Chi site used by RecBCD is 8 bases (GCTGGTGG), whereas in B. subtilis Chi used by AddAB is just 5 bases (AGCGG) (Wigley, 2013). Similarly, the GCGATCGC sequence is overrepresented in many cyanobacteria where one or more methylases recognize some portion of the sequence (Elhai, 2015). In Synechocystis PCC6803 the repeated sequence HIP1 (Highly Iterated Palindrome) is associated to a CGATCG-specific methylase (M.Ssp6803I) that is required for rapid growth (Elhai, 2015).

\section{Distribution of Mutagenic DNA Repair Genes in Cyanobacteria}

The above-mentioned repair systems usually remove the initial DNA lesions and restore the genetic material back to its original state. When facing many DNA injuries cells start synthesizing several proteins (endonucleases, polymerases and ligases) to accelerate DNA repair, even though there may be some incorporated errors. In this case, the replicative DNA polymerase PolIII, which cannot replicate damaged DNA, is replaced by other polymerases PolIV (encoded by $\operatorname{din} B$ ) and PolV (encoded by $u m u C D)$, which replicate damaged DNA in a mutagenic manner (Baharoglu and Mazel, 2014). 
The umuCD genes (Table 1) are unevenly distributed in cyanobacteria (Supplemental Table 1). Many strains have no umuCD, like UCYN-A (small genome) and Synechococcus PCC7002. Others possess umuCD, such as Nostoc (Anabaena) PCC7120, Synechococcus PCC7942, Synechocystis PCC6803, and the Prochlorococcus strains. A few strains harbor a duplication of umuC (Synechococcus PCC6312) and/or umuD (Cyanobium gracile PCC6307 and Synechococcus PCC6312). A. marina MBIC11017 possesses three umuC and four umuD (Swingley et al., 2008). In some cyanobacteria $u m u D C$ are clustered together, nearby ruvA (cluster $\mathrm{z}$ in Supplemental Table 1 and Supplemental Figure 1).

The gene $\operatorname{din} B$ (Table 1 ) is present in a very few cyanobacteria, such as A. marina MBIC11017, Anabaena PCC7120 and G. kilaueensis JS1 (Supplemental Table 1).

\section{Distribution of the Key E. coli-Type SOS Genes LexA and SulA in Cyanobacteria}

In many bacteria, the so-called "SOS" regulatory system is the main transcriptional circuit that detects DNA damages and regulates the repair systems according to cells needs (Baharoglu and Mazel, 2014). The SOS response is activated when RecA binds single-stranded DNA and generates a nucleofilament triggering the auto-proteolysis of the LexA regulator. In $E$. coli, LexA normally represses about 40 SOS genes (recABCD, $\operatorname{ruv} A B C$, etc.) by binding to its cognate LexA-box sequence on their promoters $\left(5^{\prime}\right.$-taCTGTatatatatACAGta- $3^{\prime}$; the upper cases indicate the conserved nucleotides), thereby precluding their transcription (Baharoglu and Mazel, 2014). One of the SOScontrolled gene codes for the key SulA protein that delays cell division until DNA damages are repaired.

The lexA gene (Table 1) is unevenly distributed in cyanobacteria. It is absent in both Arthrospira PCC8005 (Badri et al., 2015) and NIES39, and in several strains of the genus Gloeobacter, Oscillatoria and Synechococcus (including Synechococcus PCC7942, Supplemental Table 1), similarly to what found in other bacteria as H. pylori (Dorer et al., 2011) and Streptococcus pneumoniae (Baharoglu and Mazel, 2014). By contrast, lexA is present in the other tested cyanobacteria (it is duplicated in Cyanothece ATCC51142). The marine cyanobacteria of the genus Prochlorococcus and Synechococcus share a very similar lexA (clade $\mathrm{C}$ ), while other strains possess a slightly different lexA (clade B), such as A. marina MBIC11017, and both Nostoc PCC7120 and Synechocystis PCC6803 (Li et al., 2010). Interestingly, the Synechocystis PCC6803 lexA gene appeared to regulate carbon assimilation (Domain et al., 2004) and cell motility (Kizawa et al., 2016), but not DNA recombination and repair (Domain et al., 2004). Furthermore, the Nostoc PCC7120 LexA protein has a RecA-independent autoproteolytic cleavage (Kumar et al., 2015).

The sulA homolog is present in almost all cyanobacteria, to the noticeable exception of Gloeobacter violaceus PCC7421, G. kilaueensis JS1, Anabaena sp. 90 and UCYNA (Supplemental Table 1). In Synechocystis PCC6803, sulA appeared to be indispensable to cell life and division (Raynaud et al., 2004).

\section{The DNA Repair Genes Present in all Cyanobacteria Likely Encode the Core Process}

Many genes are present in the 76 studied cyanobacteria ( $m u t M$, $\operatorname{rad} A, \operatorname{rec} A, \operatorname{recFO}, \operatorname{rec} G, \operatorname{rec} N, \operatorname{ruv} A B C, s s b$, and $u v r A B C D$; Table 1 and Supplemental Table 1), including the marine strain UCYN-A that possesses the smallest genome $(1.44 \mathrm{Mb})$, and numerous marine strains Prochlorococcus and Synechococcus also endowed with a small genome (1.65-Mb). Similarly, mutS, recN, and $\operatorname{ruvC}$ are present in almost all cyanobacteria (Supplemental Table 1), namely Thermosynechococcus NK55a (absence of mutS1), Cyanothece PCC51142 (absence of recN) and ( $G$. kilaueensis JS1 absence of $\operatorname{ruvC}$ ). Consequently, we propose that the genes mutMS, $\operatorname{rad} A, \operatorname{rec} A, \operatorname{recFO}, \operatorname{rec} G, \operatorname{recN}$, ruv $A B C, s s b$, and $u v r A B C D$ encode the core DNA repair system of cyanobacteria.

A few other genes are also very well conserved (Supplemental Table 1), such as recR (absent in C. stagnale PCC7417, Cyanobacterium aponinum PCC10605 and C. epipsammum PCC9333), phr (absent in A. marina MBIC11017, and four Prochlorococcus strains: SS120, MIT9211, MIT9303 and MIT9313), and sulA (absent in UCYN-A, Anabaena sp. 90, and the two Gloeobacter strains G. violaceus PCC7421 and G. kilaueensis JS1).

By contrast, mutH is absent in all cyanobacteria (Supplemental Table 1) while $\operatorname{din} B$ occurs in only five cyanobacteria (G. kilaueensis JS1, Nostoc (Anabaena) PCC7120, N. punctiforme PCC73102, Rivularia PCC7116 and A. marina MBIC11017), and recC occurs mostly in the marine Prochlorococcus and Synechococcus strains.

\section{Acaryochloris marina MBIC11017 Possesses the Largest Panel of DNA Repair Genes Some of which Occurring in Multiple Copies in the Chromosome and/or Plasmids}

The cyanobacteria $A$. marina are unique in that they use chlorophyll d to absorb far-red light for photosynthesis. A. marina MBIC11017 possesses a large genome $(836 \mathrm{Mb})$ comprising a circular chromosome $(6.5 \mathrm{Mb})$ and nine plasmids [2.13-374 Kb, (Swingley et al., 2008)]. Consistent with its large genome size, A. marina MBIC11017 possesses almost all DNA repair genes observed in cyanobacteria, to the noticeable exception of recC. In addition to the core genes (mutMS, $\operatorname{rad} A, \operatorname{rec} A, \operatorname{recFO}, \operatorname{rec} G, \operatorname{rec} N, \operatorname{ruv} A B C, s s b$, and $u v r A B C D) A$. marina MBIC11017 has the following genes alkB, $\operatorname{din} B$ (rare in cyanobacteria), lexA, mutLTY, phr, ogt, mutLTY, recJQR, sulA, $s s b, u m u C D$, and $x e r C$ (Supplemental Table 1). Several of these genes occur in multiple copies (some located on plasmids): alkB (two copies), muts (two copies), ogt (three copies), recA (seven copies, four of them located on four distinct plasmids), recD (three copies, two of them propagated on plasmid), recJ (two copies), recQ (two copies), ssb (two copies), umuC (three copies including two plasmid copies), umuD (four copies including 
two plasmid copies), and xerC (eight copies, including six on plasmids).

The role of the DNA repair genes of A. marina MBIC11017 cannot be studied in this host because it has no genetic system yet. However, these genes can be studied in the genetic models Synechocystis PCC6803, Synechococcus PCC7942, Synechococcus PCC7002 or Nostoc (Anabaena) PCC7120, and their future DNA repair mutants. Hence, it would be interesting to study (and compare) the capability of each of the seven A. marina MBIC11017 recA genes to complement the detrimental absence of the endogenous recA gene of Synechococcus PCC7002 (Murphy et al., 1990). If so, the responses of the resulting mutants to DNA damaging agents could be further studied and compared to those of the Synechococcus PCC7002 wild-type strain.

\section{Together, the Evolutionary-Distant Genetic Models Synechocystis PCC6803, Synechococcus PCC7942, Synechococcus PCC7002 and Nostoc (Anabaena) PCC7120 Possess almost all DNA Repair Genes}

The cyanobacterial core DNA repair genes (mutMS, radA, $\operatorname{rec} A, \operatorname{recFO}, \operatorname{rec} G, \operatorname{recN}, \operatorname{ruv} A B C, s s b$, and $u v r A B C D$ ) can be investigated in any genetic models Synechocystis PCC6803, Synechococcus PCC7942, Synechococcus PCC7002 and/or Nostoc (Anabaena) PCC7120, through deletion and/or over-expression, and phenotypic analysis of the resulting mutants (resistance to DNA damaging agents, etc).

Besides the core DNA repair genes, Synechocystis PCC6803, the best-studied model, can be used to investigate alkB, lexA, $m u t L$, mutS (a second copy), mutT, phr, recBcy, recD, recQcy, sulA, umuC (two copies), and umuD (Supplemental Table 1). The genes missing in Synechocystis PCC6803 (dinB, ogt, mutY, recBec, $r e c C$, recJcy, recJec, and recQec) can be studied in the other models (Supplemental Table 1): Synechococcus PCC7942 ( $m u t Y, r e c B_{e c}$, and the two copies of ogt and recJ), Synechococcus PCC7002 ( $m u t Y, r e c B_{e c}$, the two copies of recJ and $r e c Q_{e c}$ ) and Nostoc PCC7120 (dinB, ogt, the two copies of recJ, and recQec). By contrast, $\mathrm{rec} C$ in occurring only in the marine cyanobacteria Synechococcus and Prochlorococcus, with no genetics, cannot be studied in its truly natural genetic context. Nevertheless, $\operatorname{rec} C$ can be investigated in any model cyanobacteria mentioned above.

So far only the ruvB and lexA genes of Synechocystis PCC6803 have been studied in vivo. While $\operatorname{ruvB}$ was found to operate in DNA-recombination, lexA appeared to regulate carbon assimilation (Domain et al., 2004) and cell motility (Kizawa et al., 2016) but not DNA repair (Domain et al., 2004).

\section{The E.coli-Like SOS Model for DNA Repair is Possibly Valid for the Marine Prochlorococcus and Synechococcus Cyanobacteria, but not for Gloeobacter, Synechocystis PCC6803, and Synechococcus PCC7942}

In addition to the core DNA repair genes (mutMS, radA, $\operatorname{rec} A, \operatorname{recFO}, \operatorname{recG}, \operatorname{recN}, \operatorname{ruv} A B C, s s b$, and $u v r A B C D)$ the small genomes (1.6-2.7 $\mathrm{Mb})$ of the marine cyanobacteria Prochlorococcus and Synechococcus possess several genes frequently absent in larger cyanobacterial genomes ( $\operatorname{rec} B C D$ and uти CD; Supplemental Table 1). Prochlorococcus and Synechococcus also have homologs of lexA and sulA, which encode the key E. coli SOS proteins LexA (regulation of the SOS system) and SulA (postponing of cell division until completion of DNA reparation) (Baharoglu and Mazel, 2014). Furthermore, recA and uvrA are induced by UV in Prochlorococcus and Synechococcus (no information is provided for the other genes), as occurs in E. coli (Mella-Flores et al., 2012). The distribution of DNA repair genes in Prochlorococcus and Synechococcus marine strains suggest that they may possess an E.coli-like SOS system. This hypothesis is consistent with the fact that the mutation rate of Prochlorococcus is similar to that of E. coli (Biller et al., 2015).

By contrast, several findings indicate that the E.coli-like SOS model for DNA repair is not valid for all cyanobacteria. The strongest evidence is that two cyanobacteria G. violaceus PCC7421 and G. kilaueensis JS1 have none of the two key SOS genes lexA and sulA, and they also lack alkB, $\operatorname{rec} B C$ and $\operatorname{xer} C$ (Supplemental Table 1). Similarly, Synechococcus PCC7942 (and its sister strain PCC6301) has no $\operatorname{lex} A$, alkB, $\operatorname{din} B$, and $\operatorname{rec} C D$, while Anabaena sp. 90 lacks sulA, $\operatorname{din} B$, ogt, $\operatorname{rec} B C D$ and $u m u C D$. Synechocystis PCC6803 possesses lexA, but it does not regulate DNA repair genes; it controls carbon assimilation (Domain et al., 2004) and cell motility (Kizawa et al., 2016). Furthermore, the Synechocystis PCC6803 lexA and recA genes are not induced by UV-C as occur in E. coli, actually they are downregulated by UV-C (Domain et al., 2004) [lexA is also negatively regulated by UV-B (Huang et al., 2002)]. In addition, the Synechocystis PCC6803 lexA and recA promoters have neither E. coli-like nor B. subtilis-like SOS boxes (Domain et al., 2004). Similarly, no SOS box was found in the promoter region of the Synechococcus PCC7002 recA gene (Murphy et al., 1990). Furthermore, the lexA gene of Anabaena PCC7120 was neither induced by UVB nor mitomycin C. In addition, the Synechocystis PCC6803 LexA protein has a RecA-independent autoproteolytic cleavage (Kumar et al., 2015).

In Synechococcus PCC7942, the Weigle-reactivation of irradiated phage (As-1) was neither induced by mitomycin-C nor nalidixic acid, unlike what was found in E.coli (Lanham and Houghton, 1988).

\section{CONCLUSION}

From bacteria to higher eukaryotes, cells are equipped with various conserved systems to repair DNA damages generated by their own metabolism (Imlay, 2013) or exogenous sources (solar UV, gamma radiations, chemicals, etc.). Inevitably, some DNA lesions are not correctly repaired leading to mutations that can influence cell fitness (Baharoglu and Mazel, 2014).

For historical reasons, DNA recombination and repair in prokaryotes have been mostly studied in the (nonphotosynthetic) bacterium E. coli (Baharoglu and Mazel, 2014). Unlike E.coli, cyanobacteria are continuously exposed to DNA damages generated by solar UV rays and their own 
photosynthetic metabolism (Cassier-Chauvat and Chauvat, 2015). As a likely consequence, all tested cyanobacteria were found to be more radiation resistant than $E$. coli. It is also important to study DNA recombination and repair in cyanobacteria for biotechnological purposes, since many recombinant strains appeared to be genetically unstable. They somehow managed to inactivate the (newlyintroduced) heterologous genes of industrial interest. Thus, a better understanding of DNA recombination and repair in cyanobacteria may lead to increasing the genetic stability of biotechnologically important strains, an important industrial goal.

Using a comparative genomic approach, we found that cyanobacteria possess many genes orthologous to E. coli DNA recombination and repair genes, notwithstanding the possibility that cyanobacteria have other, as yet unidentified, such genes.

These E. coli-like genes are unevenly distributed in cyanobacteria, in agreement with their wide genome diversity, in a way consistent with the size of their genomes, i.e., large genomes tend to possess more DNA repair genes than small genomes. Most of these $E$. coli-like genes are scattered throughout cyanobacterial genomes, suggesting that there is a mechanism for their coordinate regulation or that they are mostly expressed constitutively. Many DNA repair genes (mutMS, $\operatorname{radA}, \operatorname{rec} A$, $\operatorname{recFO}, \operatorname{rec} G, \operatorname{rec} N, \operatorname{ruv} A B C$, ssb, and $u v r A B C D$ ) are extremely well conserved in cyanobacteria, including in the Prochlorococcus and Synechococcus marine strains which possess very small genomes (1.44-2.7 Mb). Consequently, we propose that these genes encode the core DNA repair system of cyanobacteria.

These marine Prochlorococcus and Synechococcus cyanobacteria also have the genes $r e c B C D$ (DNA recombination), umuCD (mutational DNA replication), and the key SOS genes lexA (regulation of the SOS system) and sulA (postponing of cell division until completion of DNA reparation). These findings suggest that the marine Prochlorococcus and Synechococcus cyanobacteria may possess an E. coli-type SOS system.

In contrast, other cyanobacteria endowed with larger genomes lack some of the SOS key genes (lexA, sulA, recBCD, or umuCD). For instance, G. violaceus PCC7421 and G. kilaueensis JS1 lack lexA, recBC, and sulA (they also lack alkB and $x e r C$ ). Synechococcus PCC7942 has neither lexA nor recCD. Furthermore, the lexA gene of Synechocystis PCC6803 is not involved in the regulation of DNA repair genes (Domain et al., 2004). Collectively, these findings suggest that the E.coli-like SOS model for DNA repair is likely not valid for all cyanobacteria.

The cyanobacterium A. marina MBIC11017 possesses the most complete, and complex, set of DNA repair genes: alkB (two copies), dinB (rare in cyanobacteria), lexA, mutL, mutM, mutS (two copies), mutT, mut $Y$, ogt (three copies), phr, radA, recA (seven copies, four of them located on plasmids), recD (three copies, including two plasmidic copies), recF, recG, recJ (two copies), $\operatorname{rec} N, \operatorname{recO}, \operatorname{rec} Q$ (two copies), $\operatorname{rec} R, \operatorname{ruv} A B C$, ssb (two copies), sulA, umuC (three copies including two plasmid copies), $u m u D$ (four copies including two plasmid copies), $u v r A B C D$ and $\operatorname{xerC}$ (eight copies, including six on plasmids). However,
A. marina MBIC11017 has not all DNA repair genes, since it lacks recC. All cyanovacterial DNA repair genes naturally present (or not) in the few (evolutionary distant) genetic models Synechocystis PCC6803, Synechococcus PCC7002, Synechococcus PCC7942 and Nostoc (Anabaena) PCC7120, can be studied through deletion and/or over-expression, and analysis of the corresponding mutants (e.g., resistance to DNA damaging agents). Such works would be most welcome since little is known about DNA recombination and repair in cyanobacteria. So far, only the $\operatorname{rec} A, \operatorname{ruv} B$, and lexA genes have been studied in vivo. The recA gene appeared to be indispensable in Synechococcus PCC7002 (Murphy et al., 1990), and dispensable in Synechocystis PCC6803 (Minda et al., 2005). The Synechocystis PCC6803 recA-null mutant was sensitive to UV-C and white light. The Synechocystis PCC6803 ruvB gene was found to operate in DNA-recombination, while lexA appeared to regulate carbon assimilation (Domain et al., 2004) and cell motility (Kizawa et al., 2016), but not DNA repair (Domain et al., 2004). We hope that this review will stimulate future studies of DNA recombination and repair in cyanobacteria so as to answer the following questions, among others. Do cyanobacteria possess DNA recombination and repair genes with no counterpart in a non-photosynthetic and radiation-sensitive bacterium such as E. coli? What is the specificity/redundancy of the various copies of the repeated genes of cyanobacteria (for example of the seven $\operatorname{rec} A$ genes of $A$. marina MBIC11017)? What are the molecular mechanisms responsible for the high radiationresistance of some cyanobacteria (for instance Chroococcidiopsis). How to improve the genetic stability of cyanobacterial strains engineered for biotechnological puproses?

\section{AUTHOR CONTRIBUTION}

CC and FC conceived the study. CC, TV, and FC carried out the literature search and analyzed the data. CC, TV, and FC wrote the paper.

\section{ACKNOWLEDGMENTS}

TV was a recipient of $\mathrm{PhD}$ thesis fellowship from the CEA-Saclay France.

\section{SUPPLEMENTARY MATERIAL}

The Supplementary Material for this article can be found online at: http://journal.frontiersin.org/article/10.3389/fmicb. 2016.01809/full\#supplementary-material

Supplemental Table 1 | Distribution of DNA repair genes in cyanobacteria. The presence (indicated by the number of copies) or absence (0) of the gene is indicated along with the letters referring to the conserved gene clusters depicted in Supplemental Figure 1.

Supplemental Figure 1 | Conserved genomic organization around the DNA repair genes in cyanobacterial genomes. Genes are represented by boxes pointing in the direction of their transcription. DNA repair genes are colored in red. Genes encoding hypothetical proteins are indicated as "ho." 


\section{REFERENCES}

Abed, R. M., Al-Kharusi, S., Prigent, S., and Headley, T. (2014). Diversity, distribution and hydrocarbon biodegradation capabilities of microbial communities in oil-contaminated cyanobacterial mats from a constructed wetland. PLOS ONE 9:e114570. doi: 10.1371/journal.pone.0114570

Acharya, C., and Apte, S. K. (2013). Insights into the interactions of cyanobacteria with uranium. Photosyn. Res. 118, 83-94. doi: 10.1007/s11120-013-9928-9

Alam, J., Vrba, J. M., Cai, Y. P., Martin, J. A., Weislo, L. J., and Curtis, S. E. (1991). Characterization of the Is 895 family of insertion sequences from the cyanobacterium Anabaena Sp strain PCC 7120. J. Bacteriol. 173, 5778-5783.

Angermayr, S. A., Paszota, M., and Hellingwerf, K. J. (2012). Engineering a cyanobacterial cell factory for production of lactic acid. Appl. Environ. Microbiol. 78, 7098-7106. doi: 10.1128/AEM.01587-12

Archibald, J. M. (2009). The puzzle of plastid evolution. Curr. Biol. 19, R81-R88. doi: 10.1016/j.cub.2008.11.067

Badri, H., Monsieurs, P., Coninx, I., Wattiez, R., and Leys, N. (2015). Molecular investigation of the radiation resistance of edible cyanobacterium Arthrospira sp PCC 8005. Microbiol. Open 4, 187-207. doi: 10.1002/mbo3.229

Baharoglu, Z., and Mazel, D. (2014). SOS, the formidable strategy of bacteria against aggressions. FEMS Microbiol. Rev. 38, 1126-1145. doi: 10.1111/15746976.12077

Bennett, P. M. (2004). Genome plasticity: insertion sequence elements, transposons and integrons, and DNA rearrangement. Methods Mol. Biol. 266, 71-113. doi: 10.1385/1-59259-763-7:071

Benzerara, K., Skouri-Panet, F., Li, J. H., Férard, C., Gugger, M., Laurent, T., et al. (2014). Intracellular Ca-carbonate biomineralization is widespread in cyanobacteria. Proc. Natl. Acad. Sci. U.S.A. 111, 10933-10938. doi: 10.1073/pnas.1403510111

Berla, B. M., Saha, R., Immethun, C. M., Maranas, C. D., Moon, T. S., and Pakrasi, H. B. (2013). Synthetic biology of cyanobacteria: unique challenges and opportunities. Front. Microbiol. 4:246. doi: 10.3389/fmicb.2013.00246

Biller, S. J., Berube, P. M., Lindell, D., and Chisholm, S. W. (2015). Prochlorococcus: the structure and function of collective diversity. Nat. Rev. Microbiol. 13, 13-27. doi: $10.1038 /$ nrmicro337.8

Billi, D., Friedmann, E. I., Hofer, K. G., Caiola, M. G., and OcampoFriedmann, R. (2000). Ionizing-radiation resistance in the desiccation-tolerant cyanobacterium Chroococcidiopsis. Appl. Environ. Microbiol. 66, 1489-1492. doi: 10.1128/AEM.66.4.1489-1492.2000

Bosak, T., Liang, B., Wu, T. D., Templer, S. P., Evans, A., Vali, H., et al. (2013). Cyanobacterial diversity and activity in modern conical microbialites. Geobiology 11, 100-100. doi: 10.1111/j.1472-4669.2012.00334.x

Buljubašic, M., Zahradka, D., and Zahradka, K. (2013). RecQ helicase acts before RuvABC, RecG and XerC proteins during recombination in recBCD sbcBC mutants of Escherichia coli. Res. Microbiol. 164, 987-997. doi: 10.1016/j.resmic.2013.08.008

Buzby, J. S., Porter, R. D., and Stevens, S. E. (1983). Plasmid transformation in Agmenellum-Quadruplicatum Pr-6 - construction of biphasic plasmids and characterization of their transformation properties. J. Bacteriol. 154, 1446-1450.

Cassier-Chauvat, C., and Chauvat, F. (2014). "Cell division in cyanobacteria," in The Cell Biology of Cyanobacteria, eds E. Flores and A. Herrero (Norfolk, UK: Caister Academic Press), 7-27.

Cassier-Chauvat, C., and Chauvat, F. (2015). Responses to oxidative and heavy metal stresses in cyanobacteria: recent advances. Int. J. Mol. Sci. 16, 871-886. doi: $10.3390 /$ ijms 16010871

Cassier-Chauvat, C., Poncelet, M., and Chauvat, F. (1997). Three insertion sequences from the cyanobacterium Synechocystis PCC6803 support the occurrence of horizontal DNA transfer among bacteria. Gene 195, 257-266. doi: 10.1016/S0378-1119(97)00165-0

Chauvat, F., Corre, B., Herdman, M., and Josetespardellier, F. (1982). Energetic and metabolic requirements for the germination of akinetes of the cyanobacterium Nostoc PCC7524. Arch. Microbiol. 133, 44-49. doi: 10.1007/BF00943768

Chauvat, F., Devries, L., Vanderende, A., and Vanarkel, G. A. (1986). A host-vector system for gene cloning in the cyanobacterium synechocystis Pcc 6803. Mol. Gen. Genet. 204, 185-191. doi: 10.1007/BF00330208

Chauvat, F., Labarre, J., Ferino, F., Thuriaux, P., and Fromageot, P. (1988). "Gene transfer to the cyanobacterium Synechocystis PCC6803," in Algal Biotechnology, eds T. Stadler, J. Mollion, M.-C. Verdus, Y. Karamanos, H. Morvan, and D. Christiaen (London: Elsevier Applied Science), 89-99.

Choi, J. W., Yim, S. S., Kim, M. J., and Jeong, K. J. (2015). Enhanced production of recombinant proteins with Corynebacterium glutamicum by deletion of insertion sequences (IS elements). Microb. Cell Fact. 14, 207. doi: 10.1186/s12934-015-0401-7

Dagan, T., Roettger, M., Stucken, K., Landan, G., Koch, R., Major, P., et al. (2013). Genomes of Stigonematalean cyanobacteria (subsection V) and the evolution of oxygenic photosynthesis from prokaryotes to plastids. Genome Biol. Evol. 5, 31-44. doi: 10.1093/gbe/evs117

Dittmann, E., Gugger, M., Sivonen, K., and Fewer, D. P. (2015). Natural product biosynthetic diversity and comparative genomics of the cyanobacteria. Trends Microbiol. 23, 642-652. doi: 10.1016/j.tim.2015.07.008

Domain, F., Houot, L., Chauvat, F., and Cassier-Chauvat, C. (2004). Function and regulation of the cyanobacterial genes lexA, recA and $\operatorname{ruv} B$ : LexA is critical to the survival of cells facing inorganic carbon starvation. Mol. Microbiol. 53, 65-80. doi: 10.1111/j.1365-2958.2004.04100.x

Dorer, M. S., Sessler, T. H., and Salama, N. R. (2011). Recombination and DNA repair in Helicobacter pylori. Ann. Rev. Microbiol. 65, 329-348. doi: 10.1146/annurev-micro-090110-102931

Dutheil, J., Saenkham, P., Sakr, S., Leplat, C., Ortega-Ramos, M., Bottin, H., et al. (2012). The AbrB2 autorepressor, expressed from an atypical promoter, represses the hydrogenase operon to regulate hydrogen production in Synechocystis strain PCC6803. J. Bacteriol. 194, 5423-5433. doi: 10.1128/JB.00543-12

Elhai, J. (2015). Highly iterated palindromic sequences (HIPs) and their relationship to DNA methyltransferases. Life5, 921-948. doi: 10.3390/life5010921

Ferino, F., and Chauvat, F. (1989). A promoter-probe vector-host system for the cyanobacterium, Synechocystis PCC6803. Gene 84, 257-266. doi: 10.1016/03781119(89)90499-X

Figge, R. M., Cassier-Chauvat, C., Chauvat, F., and Cerff, R. (2000). The carbon metabolism-controlled Synechocystis gap2 gene harbours a conserved enhancer element and a Gram-positive-like -16 promoter box retained in some chloroplast genes. Mol. Microbiol. 36, 44-54. doi: 10.1046/j.13652958.2000.01806.x

Flores, E., and Herrero, A. (2010). Compartmentalized function through cell differentiation in filamentous cyanobacteria. Nat. Rev. Microbiol. 8, 39-50. doi: $10.1038 /$ nrmicro2242

Fukuda, H., Ogawa, T., Tazaki, M., Nagahama, K., Fujii, T., Tanase, S., et al. (1992). Two reactions are simultaneously catalyzed by a single enzyme: the argininedependent simultaneous formation of two products, ethylene and succinate, from 2-oxoglutarate by an enzyme from Pseudomonas syringae. Biochem. Biophys. Res. Commun. 188, 483-489. doi: 10.1016/0006-291X(92)91081-Z

Gao, K. S. (1998). Chinese studies on the edible blue-green alga, Nostoc flagelliforme: a review. J. Appl. Phycol. 10, 37-49. doi: 10.1023/A:1008014424247

Gellert, M., and Nash, H. (1987). Communication between Segments of DNA during Site-Specific Recombination. Nature 325, 401-411. doi: $10.1038 / 325401 \mathrm{a} 0$

Griese, M., Lange, C., and Soppa, J. (2011). Ploidy in cyanobacteria. FEMS Microbiol. Lett. 323, 124-131. doi: 10.1111/j.1574-6968.2011.02368.x

Grigorieva, G., and Shestakov, S. (1982). Transformation in the cyanobacterium Synechocystis sp 6803. FEMS Microbiol. Lett. 13, 367-370. doi: 10.1111/j.15746968.1982.tb08289.x

Grizeau, D., Bui, L. A., Dupré, C., and Legrand, J. (2015). Ammonium photoproduction by heterocytous cyanobacteria: potentials and constraints. Crit Rev Biotechnol, 1-12. doi: 10.3109/07388551.2014.1002380

Hamilton, T. L., Bryant, D. A., and Macalady, J. L. (2016). The role of biology in planetary evolution: cyanobacterial primary production in lowoxygen Proterozoic oceans. Environ. Microbiol. 18, 325-340. doi: 10.1111/14622920.13118

Hernández-Prieto, M. A., Semeniuk, T. A., Giner-Lamia, J., and Futschik, M. E. (2016). The transcriptional landscape of the photosynthetic model cyanobacterium Synechocystis sp. PCC6803. Sci. Rep. 6:22168. doi: $10.1038 /$ srep22168

Hess, W. R. (2011). Cyanobacterial genomics for ecology and biotechnology. Curr. Opin. Microbiol. 14, 608-614. doi: 10.1016/j.mib.2011.07.024 
Holder, I. T., Wagner, S., Xiong, P., Sinn, M., Frickey, T., Meyer, A., et al. (2015). Intrastrand triplex DNA repeats in bacteria: a source of genomic instability. Nucleic Acids Res. 43, 10126-10142. doi: 10.1093/nar/gk v1017

Hu, S., Wang, J., Wang, L., Zhang, C. C., and Chen, W. L. (2015). Dynamics and cell-type specificity of the DNA double-strand break repair Protein RecN in the developmental cyanobacterium Anabaena sp. Strain PCC 7120. PLoS ONE 10:e0139362. doi: 10.1371/journal.pone.0139362

Huang, H. H., Camsund, D., Lindblad, P., and Heidorn, T. (2010). Design and characterization of molecular tools for a synthetic biology approach towards developing cyanobacterial biotechnology. Nucl. Acid Res. 38, 2577-2593. doi: $10.1093 / \mathrm{nar} / \mathrm{gkq} 164$

Huang, L., McCluskey, M. P., Ni, H., and LaRossa, R. A. (2002). Global gene expression profiles of the cyanobacterium Synechocystis sp. strain PCC 6803 in response to irradiation with UV-B and white light. J. Bacteriol. 184, 6845-6858. doi: $10.1128 /$ JB.184.24.6845-6858.2002

Imlay, J. A. (2013). The molecular mechanisms and physiological consequences of oxidative stress: lessons from a model bacterium. Nat. Rev. Microbiol. 11, 443-454. doi: 10.1038/nrmicro3032

Ito, H., Watanabe, H., Takehisa, M., and Iizuka, H. (1983). Isolation and identification of radiation-resistant cocci belonging to the Genus Deinococcus from sewage sludges and animal feeds. Agric. Biol. Chem. 47, 1239-1247. doi: 10.1271/bbb1961.47.1239

Jacobsen, J. H., and Frigaard, N. U. (2014). Engineering of photosynthetic mannitol biosynthesis from CO2 in a cyanobacterium. Metab. Eng. 21, 60-70. doi: 10.1016/j.ymben.2013.11.004

Jansson, C., and Northen, T. (2010). Calcifying cyanobacteria-the potential of biomineralization for carbon capture and storage. Curr. Opin. Biotechnol. 21, 365-371. doi: 10.1016/j.copbio.2010.03.017

Kanesaki, Y., Shiwa, Y., Tajima, N., Suzuki, M., Watanabe, S., Sato, N., et al. (2012). Identification of substrain-specific mutations by massively parallel wholegenome resequencing of Synechocystis sp. PCC 6803. DNA Res. 19, 67-79. doi: 10.1093/dnares/dsr042

Kirti, A., Rajaram, H., and Apte, S. K. (2013). Characterization of two naturally truncated, Ssb-like proteins from the nitrogen-fixing cyanobacterium, Anabaena sp. PCC7120. Photosynth. Res. 118, 147-154. doi: 10.1007/s11120013-9904-4

Kizawa, A., Kawahara, A., Takimura, Y., Nishiyama, Y., and Hihara, Y. (2016). RNA-seq profiling reveals novel target genes of lexa in the cyanobacterium Synechocystis sp. PCC 6803. Front. Microbiol. 7:193. doi: 10.3389/fmicb.2016.00193

Kleigrewe, K., Gerwick, L., Sherman, D. H., and Gerwick, W. H. (2016). Unique marine derived cyanobacterial biosynthetic genes for chemical diversity. Nat. Prod. Rep. 33, 348-364. doi: 10.1039/C5NP00097A

Kuhlemeier, C. J., Borrias, W. E., van den Hondel, C. A., and van Arkel, G. A. (1981). Vectors for cloning in cyanobacteria: construction and characterization of two recombinant plasmids capable of transformation of Escherichia coli K12 and Anacystis nidulans R2. Mol. Gen. Genet. 184, 249-254. doi: 10.1007/BF00272912

Kumar, A., Kirti, A., and Rajaram, H. (2015). LexA protein of cyanobacterium Anabaena sp. strain PCC7120 exhibits in vitro pH-dependent and RecAindependent autoproteolytic activity. Int. J. Biochem. Cell. Biol. 59, 84-93. doi: 10.1016/j.biocel.2014.12.003

Kusakabe, T., Tatsuke, T., Tsuruno, K., Hirokawa, Y., Atsumi, S., Liao, J. C., et al. (2013). Engineering a synthetic pathway in cyanobacteria for isopropanol production directly from carbon dioxide and light. Metab. Eng. 20, 101-108. doi: 10.1016/j.ymben.2013.09.007

Labarre, J., Chauvat, F., and Thuriaux, P. (1989). Insertional mutagenesis by random cloning of antibiotic-resistance genes into the genome of the cyanobacterium Synechocystis Strain PCC 6803. J. Bacteriol. 171, 3449-3457.

Lai, M. C., and Lan, E. I. (2015). Advances in metabolic engineering of cyanobacteria for photosynthetic biochemical production. Metabolites 5, 636-658. doi: 10.3390/metabo5040636

Lanham, P. G., and Houghton, J. A. (1988). Weigle-reactivation in a cyanobacterium (Synechococcus PCC7934) is induced by Uv but not by Mitomycin-C or Nalidixic-Acid. Photochem. Photobiol. 48, 473-475. doi: 10.1111/j.1751-1097.1988.tb02848.x
Li, H., Shen, C. R., Huang, C. H., Sung, L. Y., Wu, M. Y., and Hu, Y. C. (2016). CRISPR-Cas9 for the genome engineering of cyanobacteria and succinate production. Metab. Eng. 38, 293-302. doi: 10.1016/j.ymben.2016.09.006

Li, S., Xu, M. L., and Su, Z. C. (2010). Computational analysis of LexA regulons in Cyanobacteria. Bmc Gen 11:527. doi: 10.1186/1471-2164-11-527

Lin, S., Haas, S., Zemojtel, T., Xiao, P., Vingron, M., and Li, R. (2011). Genomewide comparison of cyanobacterial transposable elements, potential genetic diversity indicators. Gene 473, 139-149. doi: 10.1016/j.gene.2010.11.011

Mann, N., and Carr, N. G. (1974). Control of macromolecular-composition and cell-division in blue-green-alga Anacystis-Nidulans. J. Gen. Microbiol. 83, 399-405. doi: 10.1099/00221287-83-2-399

Marbouty, M., Saguez, C., Cassier-Chauvat, C., and Chauvat, F. (2009). ZipN, an FtsA-like orchestrator of divisome assembly in the model cyanobacterium Synechocystis PCC6803. Mol. Microbiol. 74, 409-420. doi: 10.1111/j.13652958.2009.06873.x

Marraccini, P., Bulteau, S., Cassier-Chauvat, C., Mermet-Bouvier, P., and Chauvat, F. (1993). A conjugative plasmid vector for promoter analysis in several cyanobacteria of the genera Synechococcus and Synechocystis. Plant Mol. Biol. 23, 905-909. doi: 10.1007/BF00021546

Marteyn, B., Domain, F., Legrain, P., Chauvat, F., and Cassier-Chauvat, C. (2009). The thioredoxin reductase-glutaredoxins-ferredoxin crossroad pathway for selenate tolerance in Synechocystis PCC6803. Mol. Microbiol. 71, 520-532. doi: 10.1111/j.1365-2958.2008.06550.x

Marteyn, B., Sakr, S., Farci, S., Bedhomme, M., Chardonnet, S., Decottignies, P., et al. (2013). The Synechocystis PCC6803 MerA-Like enzyme operates in the reduction of both mercury and uranium under the control of the Glutaredoxin 1 Enzyme. J. Bacteriol. 195, 4138-4145. doi: 10.1128/JB.00272-13

Mazouni, K., Bulteau, S., Cassier-Chauvat, C., and Chauvat, F. (1998). Promoter element spacing controls basal expression and light inducibility of the cyanobacterial secA gene. Mol. Microbiol. 30, 1113-1122. doi: 10.1046/j.13652958.1998.01145.x

Mazouni, K., Domain, F., Cassier-Chauvat, C., and Chauvat, F. (2004) Molecular analysis of the key cytokinetic components of cyanobacteria: FtsZ, ZipN and MinCDE. Mol. Microbiol. 52, 1145-1158. doi: 10.1111/j.13652958.2004.04042.x

Mazouni, K., Domain, F., Chauvat, F., and Cassier-Chauvat, C. (2003). Expression and regulation of the crucial plant-like ferredoxin of cyanobacteria. Mol. Microbiol. 49, 1019-1029. doi: 10.1046/j.1365-2958.2003.03609.x

Mella-Flores, D., Six, C., Ratin, M., Partensky, F., Boutte, C., Le Corguille, G., et al. (2012). Prochlorococcus and Synechococcus have Evolved Different Adaptive Mechanisms to Cope with Light and UV Stress. Front. Microbiol. 3:285. doi: 10.3389/fmicb.2012.00285

Mermet-Bouvier, P., Cassier-Chauvat, C., Marraccini, P., and Chauvat, F. (1993). Transfer and replication of Rsf1010-derived plasmids in several cyanobacteria of the general Synechocystis and Synechococcus. Curr. Microbiol. 27, 323-327. doi: $10.1007 / \mathrm{BF} 01568955$

Mermet-Bouvier, P., and Chauvat, F. (1994). A conditional expression vector for the cyanobacteria Synechocystis sp. strains PCC6803 and PCC6714 or Synechococcus sp. strains PCC7942 and PCC6301. Curr. Microbiol. 28, 145-148. doi: 10.1007/BF01571055

Minda, R., Ramchandani, J., Joshi, V. P., and Bhattacharjee, S. K. (2005). A homozygous recA mutant of Synechocystis PCC6803: construction strategy and characteristics eliciting a novel RecA independent UVC resistance in dark. Mol. Genet. Genomics 274, 616-624. doi: 10.1007/s00438-005-0054-z

Moseley, B. E. B., and Mattingly, A. (1971). Repair of irradiated transforming deoxyribonucleic acid in wild type and a radiation-sensitive mutant of Micrococcus-Radiodurans. J. Bacteriol. 105, 976-+.

Mühlenhoff, U. (2000). The FAPY-DNA glycosylase (Fpg) is required for survival of the cyanobacterium Synechococcus elongatus under high light irradiance. FEMS Microbiol. Lett. 187, 127-132. doi: 10.1016/S0378-1097(00)00189-0

Mühlenhoff, U., and Chauvat, F. (1996). Gene transfer and manipulation in the thermophilic cyanobacterium Synechococcus elongatus. Mol. Gen. Genet. 252, 93-100. doi: 10.1007/BF02173209

Murphy, R. C., Gasparich, G. E., Bryant, D. A., and Porter, R. D. (1990). Nucleotide-sequence and further characterization of the Synechococcus Sp Strain PCC 7002 recA Gene - complementation of a cyanobacterial RecA mutation by the Escherichia-coli recA Gene. J. Bacteriol. 172, 967-976. 
Nakasugi, K., Svenson, C. J., and Neilan, B. A. (2006). The competence gene, comF, from Synechocystis sp strain PCC 6803 is involved in natural transformation, phototactic motility and piliation. Microbiology 152, 3623-3631. doi: 10.1099/mic.0.29189-0

Narainsamy, K., Farci, S., Braun, E., Junot, C., Cassier-Chauvat, C., and Chauvat, F. (2016). Oxidative-stress detoxification and signalling in cyanobacteria: the crucial glutathione synthesis pathway supports the production of ergothioneine and ophthalmate. Mol. Microbiol. 100, 15-24. doi: 10.1111/mmi.13296

Narainsamy, K., Marteyn, B., Sakr, S., Cassier-Chauvat, C., and Chauvat, F. (2013). "Genomics of the pleïotropic glutathione system in cyanobacteria," in Genomics of Cyanobacteria, eds F. Chauvat and C. Cassier-Chauvat (Amsterdam: Academic Press, Elsevier), 157-188.

Okamoto, S., Ikeuchi, M., and Ohmori, M. (1999). Experimental analysis of recently transposed insertion sequences in the cyanobacterium Synechocystis sp. PCC 6803. DNA Res. 6, 265-273. doi: 10.1093/dnares/6.5.265

Orkwiszewski, K. G., and Kaney, A. R. (1974). Genetic transformation of the blue-green bacterium, Anacystis nidulans. Arch. Mikrobiol. 98, 31-37. doi: 10.1007/BF00425265

Ortega-Ramos, M., Jittawuttipoka, T., Saenkham, P., Czarnecka-Kwasiborski, A., Bottin, H., Cassier-Chauvat, C., et al. (2014). Engineering Synechocystis PCC6803 for hydrogen production: influence on the tolerance to oxidative and sugar stresses. PLoS ONE 9:e89372. doi: 10.1371/journal.pone.00 89372

Poncelet, M., Cassier-Chauvat, C., Leschelle, X., Bottin, H., and Chauvat, F. (1998). Targeted deletion and mutational analysis of the essential $(2 \mathrm{Fe}-2 \mathrm{~S})$ plant-like ferredoxin in Synechocystis PCC6803 by plasmid shuffling. Mol. Microbiol. 28, 813-821. doi: 10.1046/j.1365-2958.1998.00844.x

Putnam, C. D. (2016). Evolution of the methyl directed mismatch repair system in Escherichia coli. DNA Rep. 38, 32-41. doi: 10.1016/j.dnarep.2015.11.016

Raynaud, C., Cassier-Chauvat, C., Perennes, C., and Bergounioux, C. (2004). An Arabidopsis homolog of the bacterial cell division inhibitor SulA is involved in plastid division. Plant Cell 16, 1801-1811. doi: 10.1105/tpc.022335

Resende, B. C., Rebelato, A. B., D’Afonseca, V., Santos, A. R., Stutzman, T., Azevedo, V. A., et al. (2011). DNA repair in Corynebacterium model. Gene 482, 1-7. doi: 10.1016/j.gene.2011.03.008

Sakai, M., Ogawa, T., Matsuoka, M., and Fukuda, H. (1997). Photosynthetic conversion of carbon dioxide to ethylene by the recombinant cyanobacterium, Synechococcus sp. PCC 7942, which harbors a gene for the ethylene-forming enzyme of Pseudomonas syringae. J. Ferment. Bioeng. 84, 434-443. doi: 10.1016/S0922-338X(97)82004-1

Sakr, S., Dutheil, J., Saenkham, P., Bottin, H., Leplat, C., Ortega-Ramos, M., et al. (2013). The activity of the Synechocystis PCC6803 AbrB2 regulator of hydrogen production can be post-translationally controlled through glutathionylation. Int. J. Hydrogen Energ. 38, 13547-13555. doi: 10.1016/j.ijhydene.2013.07.124

Savakis, P., and Hellingwerf, K. J. (2015). Engineering cyanobacteria for direct biofuel production from $\mathrm{CO}_{2}$. Curr. Opin. Biotechnol. 33, 8-14. doi: 10.1016/j.copbio.2014.09.007

Scanlan, D. J., Ostrowski, M., Mazard, S., Dufresne, A., Garczarek, L., Hess, W. R., et al. (2009). Ecological genomics of marine picocyanobacteria. Microbiol Mol. Biol. Rev. 73, 249-+. doi: 10.1128/MMBR.00035-08

Schopf, J. W. (2011). The paleobiological record of photosynthesis. Photosyn. Res. 107, 87-101. doi: 10.1007/s11120-010-9577-1

Schulze, K., Lang, I., Enke, H., Grohme, D., and Frohme, M. (2015). The use of fluorescence microscopy and image analysis for rapid detection of nonproducing revertant cells of Synechocystis sp. PCC6803 and Synechococcus sp. PCC7002. BMC Res Notes 8:160. doi: 10.1186/s13104-015-1112-1

Shih, P. M., Wu, D. Y., Latifi, A., Axen, S. D., Fewer, D. P., Talla, E., et al. (2013). Improving the coverage of the cyanobacterial phylum using diversitydriven genome sequencing. Proc. Natl. Acad. Sci. U.S.A. 110, 1053-1058. doi: $10.1073 /$ pnas. 1217107110

Singh, H., Fernandes, T., and Apte, S. K. (2010). Unusual radioresistance of nitrogen-fixing cultures of Anabaena strains. J. Biosci. 35, 427-434. doi: $10.1007 /$ s12038-010-0048-9
Singh, J. S., Kumar, A., Rai, A. N., and Singh, D. P. (2016). Cyanobacteria: a precious bio-resource in agriculture, ecosystem, and environmental sustainability. Front. Microbiol. 7:529. doi: 10.3389/fmicb.2016.00529

Stevens, S. E., and Porter, R. D. (1980). Transformation in Agmenellum quadruplicatum. Proc. Natl. Acad. Sci. U.S.A. 77, 6052-6056. doi: 10.1073/pnas.77.10.6052

Sun, Z., and Blanchard, J. L. (2014). Strong genome-wide selection early in the evolution of Prochlorococcus resulted in a reduced genome through the loss of a large number of small effect genes. PLoS ONE 9:e88837. doi: 10.1371/journal.pone.0088837

Swingley, W. D., Chen, M., Cheung, P. C., Conrad, A. L., Dejesa, L. C., Hao, J., et al. (2008). Niche adaptation and genome expansion in the chlorophyll dproducing cyanobacterium Acaryochloris marina. Proc. Natl. Acad. Sci. U.S.A. 105, 2005-2010. doi: 10.1073/pnas.0709772105

Takahama, K., Matsuoka, M., Nagahama, K., and Ogawa, T. (2003). Construction and analysis of a recombinant cyanobacterium expressing a chromosomally inserted gene for an ethylene-forming enzyme at the psbAI locus. J. Biosci. Bioeng. 95, 302-305. doi: 10.1016/S1389-1723(03)80034-8

Taton, A., Unglaub, F., Wright, N. E., Zeng, W. Y., Paz-Yepes, J., Brahamsha, B., et al. (2014). Broad-host-range vector system for synthetic biology and biotechnology in cyanobacteria. Nucleic Acids Res. 42, e136. doi: 10.1093/nar/gku673

Tolonen, A. C., Liszt, G. B., and Hess, W. R. (2006). Genetic manipulation of Prochlorococcus strain MIT9313: green fluorescent protein expression from an RSF1010 plasmid and Tn5 transposition. Appl. Environ. Microbiol. 72, 7607-7613. doi: 10.1128/AEM.02034-06

Trautmann, D., Voss, B., Wilde, A., Al-Babili, S., and Hess, W. R. (2012). Microevolution in cyanobacteria: re-sequencing a motile substrain of Synechocystis sp. PCC 6803. DNA Res. 19, 435-448. doi: 10.1093/dnares/dss024

Watanabe, S., Ohbayashi, R., Kanesaki, Y., Saito, N., Chibazakura, T., Soga, T., et al. (2015). Intensive DNA Replication and Metabolism during the Lag Phase in Cyanobacteria. PLoS ONE 10:e0136800. doi: 10.1371/journal.pone.0136800

Wendt, K. E., Ungerer, J., Cobb, R. E., Zhao, H., and Pakrasi, H. B. (2016). CRISPR/Cas9 mediated targeted mutagenesis of the fast growing cyanobacterium Synechococcus elongatus UTEX 2973. Microb. Cell Fact. 15, 115. doi: 10.1186/s12934-016-0514-7

Wigley, D. B. (2013). Bacterial DNA repair: recent insights into the mechanism of RecBCD, AddAB and AdnAB. Nat. Rev. Microbiol. 11, 9-13. doi: $10.1038 /$ nrmicro2917

Williams, P. G. (2009). Panning for chemical gold: marine bacteria as a source of new therapeutics. Trends Biotechnol. 27, 45-52. doi: 10.1016/j.tibtech.2008.10.005

Yoshihara, S., Geng, X. X., Okamoto, S., Yura, K., Murata, T., Go, M. et al. (2001). Mutational analysis of genes involved in pilus structure, motility and transformation competency in the unicellular motile cyanobacterium Synechocystis sp PCC 6803. Plant Cell Physiol. 42, 63-73. doi: $10.1093 / \mathrm{pcp} / \mathrm{pce} 007$

Zehr, J. P. (2011). Nitrogen fixation by marine cyanobacteria. Trends Microbiol. 19, 162-173. doi: 10.1016/j.tim.2010.12.004

Zhou, J., Zhu, T., Cai, Z., and Li, Y. (2016). From cyanochemicals to cyanofactories: a review and perspective. Microb. Cell Fact. 15, 2. doi: 10.1186/s12934-0150405-3

Conflict of Interest Statement: The authors declare that the research was conducted in the absence of any commercial or financial relationships that could be construed as a potential conflict of interest.

Copyright (c) 2016 Cassier-Chauvat, Veaudor and Chauvat. This is an open-access article distributed under the terms of the Creative Commons Attribution License (CC $B Y)$. The use, distribution or reproduction in other forums is permitted, provided the original author(s) or licensor are credited and that the original publication in this journal is cited, in accordance with accepted academic practice. No use, distribution or reproduction is permitted which does not comply with these terms. 